\title{
Retained Herrick Plug
}

\author{
Justin B. Hellman Edward Bradley Strong Lily Koo Lin \\ Department of Ophthalmology and Vision Sciences, University of California Davis Medical \\ Center, Sacramento, CA, USA
}

\section{Keywords}

Retained Herrick plug · Tearing · Dacryocystorhinostomy · Endoscopic

\begin{abstract}
A 79-year-old female with a history of keratoconjunctivitis sicca presented with several years of epiphora of both eyes. Thirteen years earlier, intracanalicular Herrick lacrimal plugs (Lacrimedics, Eastsound, WA, USA) had been placed in both eyes to treat her dry eye syndrome. After 13 years the patient felt the epiphora was intolerable and underwent endoscopic dacryocystorhinostomy (DCR) of the left, then the right side. Intraoperatively, during the right endoscopic DCR, a Herrick lacrimal plug was found in the common canaliculus into the lacrimal sac. Postoperatively, the patient did well with improved epiphora. The Herrick plug is designed to be intracanalicular, and this case illustrates that the plug can migrate and be retained for many years. Collared punctal plugs have a lower risk of this type of complication.
\end{abstract}

(C) 2018 The Author(s)

Published by S. Karger AG, Basel

\section{Case Report}

A 79-year-old female with a history of keratoconjunctivitis sicca presented with several years of intermittent epiphora of both eyes. Thirteen years earlier, intracanalicular Herrick lacrimal plugs had been placed in both eyes to treat her dry eye syndrome. One year later she complained of epiphora in the left eye and the plug could not be removed via irrigation. The 


\section{Case Reports in Ophthalmology}

patient elected not to pursue further treatment. On presentation, punctal irrigation showed an obstructed inferior canaliculus with a patent nasolacrimal duct in the right eye and complete obstruction of the nasolacrimal duct in the left eye. No punctal plugs were dislodged with irrigation. The patient elected to undergo endoscopic dacryocystorhinostomy (DCR) in the left eye and postoperatively had resolution of epiphora. No plug was identified during the procedure, though it may still be lodged in the nasolacrimal duct. Over the next several months she noticed increased epiphora in the right eye, so endoscopic DCR was planned for that eye. Intraoperatively, probing of the inferior canaliculus confirmed a distal obstruction. Endoscopy revealed a Herrick lacrimal plug extending from the common canaliculus into the lacrimal sac (Fig. 1a). Postoperatively the patient did well with improved epiphora. This case is a reminder of a potential complication of intracanalicular punctal plugs, particularly the Herrick lacrimal plug. Collared punctal plugs have a much lower risk of becoming lodged in the tear drainage system and can be easily removed in the setting of epiphora. We feel that they are a safer alternative for punctal occlusion.

\section{Discussion}

Foreign bodies obstructing the lacrimal drainage system are not an uncommon cause of dacryocystitis or epiphora and can be identified on endoscopic DCR. The most commonly detected mass, though not a foreign body, is a dacryolith, found in $9.9 \%$ of endoscopic DCRs [1]. Foreign bodies in the lacrimal drainage system that have been reported include a retained BB and self-inserted fishing wire [2,3]. However, the majority of obstructions due to a foreign body are iatrogenic. A careful history in any patient presenting with dacryocystitis or epiphora can raise one's suspicion of a retained iatrogenic foreign body. In patients with a history of reconstructive surgery of the medial orbital wall, retained postauricular cartilage [4] and a silastic sheet [5] have been detected in the lacrimal sac. In patients with a history of intubation with silicone stents or DCR, pieces of silicone tubing [6], a Griffiths' collar button stent used to maintain the nasal ostium [7], and retained gauze [8] have been identified in the lacrimal system. Other iatrogenic foreign bodies that have been reported include a piece of a metallic punctal dilator [9], and more common than any of the above, retained intracanalicular plugs [10].

Keratoconjunctivitis sicca is one of the most common diagnoses treated in a comprehensive ophthalmology practice. Patients who fail to respond to conservative therapy with artificial tears often undergo plugging of the lacrimal system in order to augment a low tear film and maintain ocular surface moisture. Though there are several variations, the two primary categories of lacrimal plugs are collared punctal plugs and intracanalicular plugs. Collared plugs are visible on examination of the puncta, while intracanalicular plugs are inserted deeper and are not visible externally.

An obvious potential side effect of lacrimal plug placement is epiphora. When this occurs, the punctal plugs can be removed. Collared plugs are removed manually with forceps while intracanalicular plugs are removed via punctal dilation and irrigation. Unfortunately, in many cases intracanalicular plugs cannot be dislodged with irrigation and require canaliculotomy or DCR to retrieve them. One case series reported 66 such cases of retained intracanalicular plugs. None of the patients in the control group of 336 eyes with collared punctal plugs required surgical removal [10]. For the treatment of keratoconjunctivitis sicca, we feel that collared punctal plugs are a much safer option. 
While discovering a foreign body during endoscopic DCR is not common, it is something that a surgeon can encounter. Most of the time the cause will be iatrogenic, and the most commonly encountered iatrogenic foreign body will be an intracanalicular plug. Fortunately, removal of the foreign body during DCR is associated with excellent outcomes.

\section{Statement of Ethics}

The authors confirm that any aspect of the work covered in this paper has been conducted with the ethical approval of all relevant bodies and that such approvals are acknowledged within the paper.

\section{Disclosure Statement}

The authors confirm that there are no known conflicts of interest and that there has been no financial support for this work that could have influenced its outcome.

\section{References}

1 Komínek P, Červenka S, Zeleník K, Pniak T, Tomášková H, Matoušek P. Lacrimal sac dacryolith (76 cases): a predictive factor for successful endonasal dacryocystorhinostomy? Eur Arch Otorhinolaryngol. 2014 Jun;271(6):1595-9.

2 Lee LB, Dutton JJ. Chronic, recurrent dacryocystitis from a BB in the lacrimal sac. Ophthal Plast Reconstr Surg. 2014 Mar-Apr;30(2):e40-1.

3 Nakao I, Hirata A, Okinami S, Kojima K. A case of self-insertion of a foreign object into the lacrimal sac. Graefes Arch Clin Exp Ophthalmol. 2013 May;251(5):1443-4.

4 Yuksel N, Akcay E, Kilicarslan A, Ozen U, Ozturk F. A Surprise in the Lacrimal Sac. Middle East Afr J Ophthalmol. 2016 Jul-Sep;23(3):268-70.

5 Choi JS, Lee JH, Paik HJ. A silastic sheet found during endoscopic transnasal dacryocystorhinostomy for acute dacryocystitis. Korean J Ophthalmol. 2006 Mar;20(1):65-9.

6 Heichel J, Struck HG, Bredehorn-Mayr T. [Chronic dacryocystitis in a pediatric patient: transcanalicular endoscopic-assisted removal of iatrogenic foreign body from the lacrimal sac]. Ophthalmologe. 2014 Sep;111(9):862-5.

7 Comez AT, Guclu 0, Gencer B, Kara S, Tufan HA. Recurrent dacryocystitis and lacrimocutaneous fistula caused by a retained Griffiths' collar button stent. Orbit. 2014 Apr;33(2):142-4.

8 Shoaib KK. An enlarging mass due to a retained gauze piece - an unusual complication of dacryocystorhinostomy. Can J Ophthalmol. 2011 Aug;46(4):372-3.

9 Gupta D, Whittet HB, Sood S, Maitra S. Dacryocystitis secondary to an iatrogenic foreign body in the lacrimal apparatus. Ear Nose Throat J. 2009 Jul;88(7):1001-9.

10 Mazow ML, McCall T, Prager TC. Lodged intracanalicular plugs as a cause of lacrimal obstruction. Ophthal Plast Reconstr Surg. 2007 Mar-Apr;23(2):138-42. 


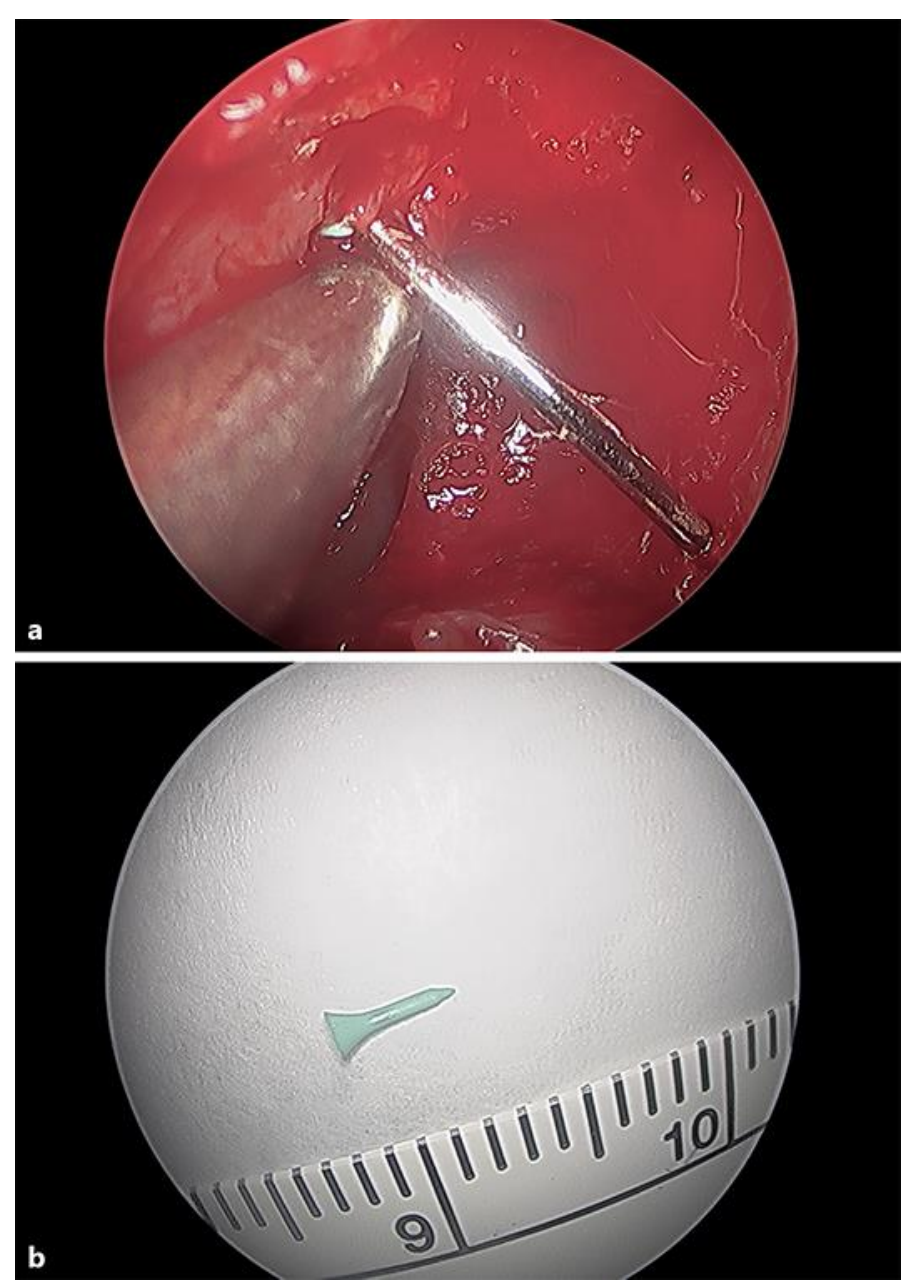

Fig. 1. a Endoscopic view of the Bowman probe coming out of the opened lacrimal sac and the Herrick plug at the common canaliculus. b Herrick plug. 